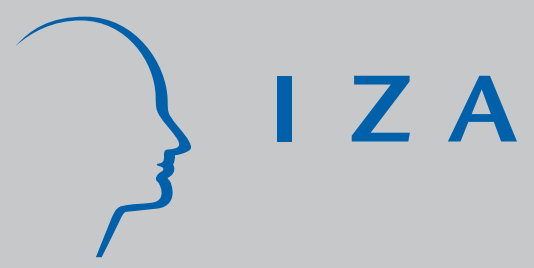

IZA DP No. 358

Bismarck versus Beveridge: Which Unemployment Compensation System is More Prone to Labor Market Shocks?

Thomas Beissinger

Oliver Buesse

September 2001 


\title{
Bismarck versus Beveridge: Which Unemployment Compensation System is More Prone to Labor Market Shocks?
}

\author{
Thomas Beissinger \\ Oliver Buesse \\ University of Regensburg \\ Discussion Paper No. 358 \\ September 2001 \\ IZA \\ P.O. Box 7240 \\ D-53072 Bonn \\ Germany \\ Tel.: +49-228-3894-0 \\ Fax: +49-228-3894-210 \\ Email: iza@iza.org
}

University of Regensburg and IZA, Bonn

This Discussion Paper is issued within the framework of IZA's research area The Welfare State and Labor Markets. Any opinions expressed here are those of the author(s) and not those of the institute. Research disseminated by IZA may include views on policy, but the institute itself takes no institutional policy positions.

The Institute for the Study of Labor (IZA) in Bonn is a local and virtual international research center and a place of communication between science, politics and business. IZA is an independent, nonprofit limited liability company (Gesellschaft mit beschränkter Haftung) supported by the Deutsche Post AG. The center is associated with the University of Bonn and offers a stimulating research environment through its research networks, research support, and visitors and doctoral programs. IZA engages in (i) original and internationally competitive research in all fields of labor economics, (ii) development of policy concepts, and (iii) dissemination of research results and concepts to the interested public. The current research program deals with (1) mobility and flexibility of labor markets, (2) internationalization of labor markets and European integration, (3) the welfare state and labor markets, (4) labor markets in transition, (5) the future of work, (6) project evaluation and (7) general labor economics.

IZA Discussion Papers often represent preliminary work and are circulated to encourage discussion. Citation of such a paper should account for its provisional character. 
IZA Discussion Paper No. 358

September 2001

\section{ABSTRACT \\ Bismarck versus Beveridge: \\ Which Unemployment Compensation System is More Prone to Labor Market Shocks?*}

Based on a model with imperfectly competitive labor and product markets the real consequences of labor market shocks for economies with either an earnings-related or flatrate unemployment compensation system are considered. A distinctive feature of the analysis is the comparison of both unemployment compensation systems in a two-country setting. It is demonstrated that the performance of a system with earnings-related or flat-rate unemployment benefits depends on whether the labor market shock is provoked in the home country or originates from abroad. We also point out how our results extend to two-tier unemployment compensation systems which differ with respect to the relative importance of earnings-related and flat-rate benefits.

JEL Classification: E24, F41, J23, J51, J65

Keywords: $\quad$ Earnings-related benefits, flat-rate benefits, unemployment, open economy, monopolistic competition, wage bargaining

Thomas Beissinger

University of Regensburg

Department of Economics

93040 Regensburg

Germany

Tel.: +499419432740

Fax: +499419432735

Email: Thomas.Beissionger@wiwi.uni-regensburg.de

\footnotetext{
* We are grateful to Laszlo Goerke and Johannes Ludsteck for valuable comments and suggestions.
} 


\section{Introduction}

There are two basic principles governing unemployment compensation: the insurance principle and the welfare principle (cf. Schmid, Reissert (1996)). The main objective of an unemployment compensation system based on the insurance principle is "income smoothing", i.e. the compensation for lost earnings and the provision of some form of status maintenance. In contrast, unemployment compensation guided by the welfare principle focuses more on income redistribution or the alleviation of poverty by providing a minimum income. In an insurance system benefits are linked to previous earnings and sometimes also to the duration of previous employment. In the literature such a system is known as the Bismarckian model of unemployment insurance (cf. Ploug, Kvist (1996)). On the other hand, a system emphasizing the welfare aspect is usually based on flat-rate benefits, as suggested by Beveridge (see the Beveridge Report (1942)).

In most OECD countries a two-tier unemployment compensation system is implemented which takes account of both principles. In an initial period of unemployment, unemployment benefits which are related to previous earnings are usually paid. If the spell of unemployment lasts longer or if eligibility criteria for unemployment benefits are not met, unemployment assistance benefits are paid, which are usually independent of previous earnings and contribution payments. ${ }^{1}$ In many aspects, the unemployment compensation system in the UK corresponds most closely to the Beveridgean system, since both unemployment benefits and unemployment assistance are implemented as flat-rate payments. In contrast, the Bismarckian system is most closely realized in Germany, since both unemployment benefits and unemployment assistance are earnings-related. ${ }^{2}$

In this paper we compare the consequences of labor market shocks with respect to real wages and unemployment for economies with either an earnings-related or flat-rate unemployment compensation system. The shocks we consider are changes in the relative bargaining power of labor unions, the generosity of unemployment benefits or labor unions'

\footnotetext{
${ }^{1}$ For an international comparison of unemployment compensation systems see, for instance, Schmid, Reissert (1996), Schmid et al. (1992) and Ploug, Kvist (1996).

${ }^{2}$ For a comparison of unemployment benefit policies in Great Britain and Germany see, for example, Clasen (1994).
} 
preferences. A distinctive feature of our analysis is the comparison of both unemployment compensation systems in a two-country setting. It is demonstrated that the performance of the Beveridgean and Bismarckian systems crucially depends on whether the labor market shock is provoked in the home country or originates from abroad. We also point out how our results extend to two-tier unemployment compensation systems which differ with respect to the relative importance of earnings-related and flat-rate benefits.

Only recently attention has been paid to the dependence of results and policy conclusions on the institutional setup of the unemployment compensation system. ${ }^{3}$ For example, Schluter (1997), by adopting a search-theoretic general equilibrium framework, scrutinizes the relative performance of earnings-related and flat-rate benefits with respect to the alleviation of poverty and the reduction in income inequality. Goerke (2000), Goerke, Madsen (2000) and Heer, Morgenstern (2000) analyze the employment and real wage effects which result when a country increases the share of earnings-related unemployment benefits relative to flat-rate transfers. Bräuninger (2001) establishes a link between the type of unemployment compensation system and the employment performance of different skill groups. Cremer and Pestieau (1998), focusing on payroll tax competition, develop a political economy approach where the type of unemployment compensation (Beveridgean or Bismarckian) is chosen "behind the veil of ignorance". All these models only deal with the closed economy. As far as we know, up until now no comparisons of both unemployment compensation systems in multi-country models have been performed in the literature.

The remainder of the paper is organized as follows. In section 2, we introduce the theoretical framework of a two-country model with imperfectly competitive labor and product markets. As a useful benchmark case, in section 3 we first compare the performance of the Beveridgean and Bismarckian unemployment compensation systems in the closed economy, which can be interpreted as a special case of the two-country model. Section 4 then presents the comparative-static analysis for the two-country case. A comparison of the results and the discussion of some model extensions is found in section 5. Our concluding

\footnotetext{
${ }^{3}$ For a review and critique of the (early) literature on unemployment insurance see Holmlund (1998) and Atkinson, Micklewright (1991).
} 
remarks appear in section 6.

\section{The theoretical framework}

The performance of economies with different unemployment compensation systems is compared within a two-country model with imperfect competition on goods and labor markets. The goods market is integrated and characterized by monopolistic competition between firms each producing a distinct variety of a tradable product. On the labor market wage bargaining takes place at the firm level. The outcome of the wage-setting process is influenced by the relative bargaining power of firms and unions, the preferences of labor unions for employment and wages and the institutional setup of the social security system. It is assumed that countries differ with respect to these variables but otherwise are identical. The differences in wage setting may lead to country-specific wage and price levels since it is assumed that migration of the labor force is impeded by cultural and linguistic barriers. Besides the number of households, the number of firms in both countries is also exogenously given, which may be due to barriers to market entry provoked by sunk costs. For most part of the paper, the model is closed by assuming that unemployment benefits are financed by (lump-sum) taxes on the fixed stock of capital. In this case the comparative-static analysis is facilitated by the fact that the government budget constraint and the impact of taxes on the wage-setting process have not to be taken into account. In appendix A.1 it is demonstrated that the same qualitative results are, in principle, obtained if unemployment benefits are financed by a proportional tax on wage income. Hence, the assumption of a lump-sum tax on capital simplifies the exposition, but is not decisive for our results. It should also be noted that the model is intended to be a description of the longer run, where expectations are correct and nominal rigidities play no role. Our results are therefore not caused by short-run frictions. 


\subsection{Demand for goods}

It is assumed that in both countries A and B there is a exogenously given number of $F / 2$ firms and $L$ households. Household preferences are identical and comprise all goods produced in this two-country world. The representative consumer in country $h(h=A, B)$ has the following Dixit, Stiglitz (1977) type utility function:

$$
U^{h}=F^{\frac{1}{1-\eta}}\left(\sum_{i=1}^{F / 2}\left(Y_{i A}^{h}\right)^{\frac{\eta-1}{\eta}}+\sum_{i=1}^{F / 2}\left(Y_{i B}^{h}\right)^{\frac{\eta-1}{\eta}}\right)^{\frac{\eta}{\eta-1}}, \quad 1<\eta<\infty .
$$

$Y_{i j}^{h}$ denotes the quantity of good $i$ produced in country $j=A, B$ which is purchased by the representative consumer located in country $h=A, B$. The specific form of the utility function implies a constant elasticity of substitution between all goods, equal to $\eta$. Each consumer is endowed with one unit of labor which is supplied inelastically. Since migration is excluded, labor can only be supplied in the respective home country. The representative consumer of country $h$ faces the budget constraint (in real terms)

$$
\sum_{i=1}^{F / 2} p_{i A} Y_{i A}^{h}+\sum_{i=1}^{F / 2} p_{i B} Y_{i B}^{h}=\sum_{i=1}^{F / 2} p_{i h} Y_{i h}, \quad h=A, B .
$$

where $p_{i j}$ are the relative prices of the various goods in terms of the aggregate good which serves as numéraire. Since the focus of the paper is not on differences in the tax system, value added taxes and customs duties are neglected in the model. This implies that the price for a specific good is the same for consumers and producers of either country. In eq. (2) it is assumed that firms in each country are owned by domestic residents, hence the income of the representative consumer in country $h$ equals total value added in this country. Corresponding to the utility function in eq. (1) it must hold that

$$
\frac{1}{F}\left(\sum_{i=1}^{F / 2} p_{i A}^{1-\eta}+\sum_{i=1}^{F / 2} p_{i B}^{1-\eta}\right)=1
$$

By maximizing eq. (1) with respect to $Y_{i j}^{h}$ and taking account of eqs. (2) and (3), the demand functions of each consumer can be derived. To obtain the demand function for the producer of good $i$ in country $j$, one has to aggregate over the consumers of 
both countries. Defining world real income as $Y$, demand for good $Y_{i j}$ is given by the Blanchard, Kiyotaki (1987) type function

$$
Y_{i j}^{d}=p_{i j}^{-\eta} \frac{Y}{F}, \quad i=1, \ldots, F / 2, \quad j=A, B .
$$

In this model there is no rationing, so production is always equal to demand, i.e. $Y_{i j}^{d}=Y_{i j}$. In equilibrium all firms in one country are facing the same country-specific wage rate. Furthermore, firms share the same technology. Hence $p_{i j}=p_{j}$ and $Y_{j}=(F / 2) Y_{i j}$, which leads to the following inverse demand function for country $j$ :

$$
p_{j}=\left(\frac{Y}{2 Y_{j}}\right)^{1-\kappa}, \quad \kappa \equiv \frac{\eta-1}{\eta} \quad j=A, B,
$$

where $0<\kappa<1$.

\subsection{Demand for labor in every country}

Producers act as monopolistic competitors, taking account of the product demand function (4) when choosing labor demand. The behavior of firms is governed by the fact that there is a large number in every country, which implies that firms are small compared to the (national) economy as a whole. As a result, the single firm does not consider the consequences of its actions for the aggregate variables and for other firms.

Firms use the Cobb-Douglas technology $Y_{i j}=N_{i j}^{\alpha} K_{i j}^{1-\alpha}$, where $N_{i j}$ is employment and $K_{i j}$ is the (exogenously given) capital stock of firm $i$ in country $j=A, B$. Each firm chooses the employment level which equalizes marginal revenue and the real wage $w_{i j}$ (in terms of the aggregate good). This leads to the labor demand functions $N_{i j}, i=1, \ldots, F / 2$ and $j=A, B$. Since all firms are identical and face the same country-specific wage rate $w_{j}$ (to be determined later), it follows that the national levels of employment and capital stock are given by $N_{j}=(F / 2) N_{i j}$ and $K_{j}=(F / 2) K_{i j}$, respectively. Hence, demand for labor in every country is determined by

$$
N_{j}=\left[w_{j}^{-1} \alpha \kappa K_{j}^{(1-\alpha) \kappa}\left(\frac{Y}{2}\right)^{1-\kappa}\right]^{\frac{1}{1-\alpha \kappa}}, \quad j=A, B .
$$

It is important to note that labor demand is a positive function of world real income $Y$. An increase in $Y$ cet. par. leads to a higher relative price $p_{i j}$ and therefore increases marginal 
revenue of the single firm. This induces each firm to increase labor demand. Of course, $Y$ is itself an endogenous variable. With the stock of capital held fixed, variations in $Y$ are only due to variations in employment levels $N_{A}$ or $N_{B}$ (the details are derived below). As a result, changes in employment in one country will affect labor demand in the other country via the impact on world real income. Writing eq. (6) as an inverse labor-demand function and replacing employment by $N_{j}=\left(1-u_{j}\right) L$, where $L$ denotes the (exogenous) labor supply and $u_{j}$ the unemployment rate, leads to ${ }^{4}$

$$
w_{j}=n^{j}\left(u_{j}, Y\right)=\alpha \kappa\left[\left(1-u_{j}\right) L\right]^{\alpha \kappa-1} K_{j}^{(1-\alpha) \kappa}\left(\frac{Y}{2}\right)^{1-\kappa}, \quad j=A, B,
$$

with the partial derivatives

$$
n_{u_{j}}^{j}=(1-\alpha \kappa) \frac{w_{j}}{1-u_{j}}>0 \quad \text { and } \quad n_{Y}^{j}=(1-\kappa) \frac{w_{j}}{Y}>0
$$

\subsection{Wage setting in every country}

In every country wage bargaining takes place at the firm level. The utility function $V_{i j}$ of labor union $i$ in country $j$ is assumed to be given by

$$
V_{i j}=N_{i j}^{\phi_{j}}\left[w_{i j}-z_{j}\right], \quad \phi_{j}>0, \quad \forall i, j,
$$

where $\phi_{j}$ represents labor unions' preferences for employment relative to wages in country $j$. The variable $z_{j}$ denotes expected real income of a worker in country $j$, who loses his job in the firm under consideration. ${ }^{5}$ As the bargaining parties are small units compared to the whole (national) economy, $z_{j}$ is exogenous for the single firm or union. It was already pointed out that unemployment benefits are financed by taxes levied on the fixed stock of capital, whereas the discussion of a model variant with a proportional tax on wage income is delegated to appendix A.1. Since in the following payroll taxes and taxes on wage income are neglected, the real wage $w_{i j}$ is the same for employers and employees. It is obtained from maximizing the Nash product with zero fall-back positions for unions

\footnotetext{
${ }^{4}$ Since the stock of capital and the labor force is held fixed, these variables are omitted in the general labor demand function $n^{j}$.

${ }^{5}$ For similar specifications see, for example, Oswald (1985) and Manning (1991, 1995). For $\phi_{j}=1$, eq. (9) could be derived from a utilitarian union with risk-neutral members as in Layard, Nickell (1990).
} 
and firms, $V_{i j}^{\chi_{j}} \Pi_{i j}^{1-\chi_{j}}$, where $0<\chi_{j}<1$. The parameter $\chi_{j}$ denotes the bargaining power of a representative union in country $j$ and $\Pi_{i j}$ the (real) profits of the respective firm. After some rearrangement, the first-order condition for this optimization problem can be written as

$$
w_{i j}=\frac{\mu^{j}}{\mu^{j}-1} z_{j}, \quad \text { with } \quad \mu^{j}=\mu^{j}\left(\phi_{j}, \chi_{j}\right) \equiv \frac{\phi_{j}+\frac{1-\chi_{j}}{\chi_{j}} \alpha \kappa}{1-\alpha \kappa} .
$$

The partial derivatives of the function $\mu^{j}$ with respect to $\phi_{j}$ and $\chi_{j}$ are

$$
\mu_{\phi_{j}}^{j}=\frac{1}{1-\alpha \kappa}>0 \quad \text { and } \quad \mu_{\chi_{j}}^{j}=-\frac{\alpha \kappa}{(1-\alpha \kappa) \chi_{j}^{2}}<0
$$

According to eq. (10) the bargained real wage at the firm level is a mark-up on the expected alternative income $z_{j}$. In order to get a permissible solution for $w_{i j}$, it must hold that $\mu^{j}>1$. To derive the wage-setting equation for country $j$, the expected alternative income $z_{j}$ must be defined more precisely. Since migration is excluded, $z_{j}$ depends solely on variables specific to country $j$ :

$$
z_{j}=\left(1-\lambda^{j}\left(u_{j}\right)\right) w_{j}+\lambda^{j}\left(u_{j}\right) s_{j}, \quad 0<\lambda^{j}<1, \quad \lambda_{u_{j}}^{j}>0,
$$

where $w_{j}$ is the average wage level and $s_{j}$ is the real unemployment compensation in country $j$ (both in terms of the aggregate good). With probability $\lambda^{j}$ an employee loosing his job at firm $i$ will become unemployed and with probability $\left(1-\lambda^{j}\right)$ he will find a job elsewhere in the economy. The respective probabilities depend on the unemployment rate $u_{j}{ }^{6}$ Systems with earnings-related or flat-rate unemployment benefits are special cases of a two-tier unemployment compensation system, which can be defined as:

$$
s_{j}=s^{j}\left(w_{j}, \gamma_{j}, \rho_{j}, b_{j}\right)=\gamma_{j} \rho_{j} w_{j}+\left(1-\gamma_{j}\right) b_{j} \quad 0 \leq \gamma_{j} \leq 1, \quad 0<\rho_{j}<1, \quad b_{j}>0 .
$$

In this equation $\gamma_{j}$ denotes the percentage of unemployed who receive earnings-related unemployment benefits, $\rho_{j}$ is the replacement ratio and $b_{j}$ denotes flat-rate unemployment

\footnotetext{
${ }^{6}$ From an intertemporal framework it follows that the probability $\lambda_{j}$ also depends on the discount rate and the quit rate (see, for instance, Beissinger and Egger (2000)). Country-specific differences with respect to these variables lead to different functions $\lambda_{j}$. The function $\lambda_{j}$ may also reflect differences in matching technologies between countries.
} 
benefits (in real terms). ${ }^{7}$ For $\gamma_{j}=1$ a pure earnings-related unemployment compensation system is obtained, whereas $\gamma_{j}=0$ implies that all benefits are paid as flat-rate transfers. Since within a country all firms and unions are identical, $w_{i j}=w_{j}$ must hold in equilibrium. Using the definitions of $z_{j}$ in the firm-level wage equation (10), one gets

$$
w_{j}-\frac{\mu^{j} \lambda^{j}}{\mu^{j} \lambda^{j}-1} s^{j}\left(w_{j}, \gamma_{j}, \rho_{j}, b_{j}\right)=0
$$

Inserting eq. (12) in this equation, the national wage-setting equation is given by

$$
w_{j}\left[\frac{\mu^{j}\left(\phi_{j}, \chi_{j}\right) \lambda^{j}\left(u_{j}\right)\left[1-\gamma_{j} \rho_{j}\right]-1}{\mu^{j}\left(\phi_{j}, \chi_{j}\right) \lambda^{j}\left(u_{j}\right)}\right]-\left(1-\gamma_{j}\right) b_{j}=0 .
$$

In order to guarantee that $w_{j}>0$ it must be assumed that $\mu^{j} \lambda^{j}\left(1-\gamma_{j} \rho_{j}\right)-1>0$, which also implies that $\mu^{j} \lambda^{j}-1>0$.

Earnings-related unemployment compensation system: If $\gamma_{j}=1$, it can be seen from eq. (14) that the wage-setting equation alone already determines the level of unemployment. As a result, the wage-setting curve in real wage-unemployment space is vertical at the unemployment rate $u_{j}=u^{j}\left(\phi_{j}, \chi_{j}, \rho_{j}\right)$, which is given by

$$
\left[1-\rho_{j}\right] \mu^{j}\left(\phi_{j}, \chi_{j}\right) \lambda^{j}\left(u^{j}\left(\phi_{j}, \chi_{j}, \rho_{j}\right)\right)-1 \equiv 0
$$

with the partial derivatives

$$
u_{\phi_{j}}^{j}=\frac{-\lambda^{j} \mu_{\phi_{j}}^{j}}{\mu^{j} \lambda_{u_{j}}^{j}}<0, \quad u_{\chi_{j}}^{j}=\frac{-\lambda^{j} \mu_{\chi_{j}}^{j}}{\mu^{j} \lambda_{u_{j}}^{j}}>0, \quad u_{\rho_{j}}^{j}=\frac{\lambda^{j}}{\left(1-\rho_{j}\right) \lambda_{u_{j}}^{j}}>0 .
$$

Flat-rate unemployment compensation system: With $\gamma_{j}=0$ the wage-setting equation can be written as

$$
w_{j}=w^{j}\left(u_{j}, \phi_{j}, \chi_{j}, b_{j}\right)=\frac{\mu^{j}\left(\phi_{j}, \chi_{j}\right) \lambda^{j}\left(u_{j}\right)}{\mu^{j}\left(\phi_{j}, \chi_{j}\right) \lambda^{j}\left(u_{j}\right)-1} b_{j}
$$

\footnotetext{
${ }^{7}$ In accordance with the literature, in eq. (12) it is assumed that earnings-related benefits are a function of the average wage level in the respective country. This guarantees that $z_{j}$ is exogenous in the firm level bargain. Beissinger, Egger (2000) discuss within a dynamic wage bargaining model the complications which arise if this assumption is abandoned.
} 
with the partial derivatives

$$
\begin{array}{rlrl}
w_{u_{j}}^{j} & =-\frac{\lambda_{u_{j}}^{j} \mu^{j}}{\left(\mu^{j} \lambda^{j}-1\right)^{2}} b_{j}<0 & w_{\phi_{j}}^{j} & =-\frac{\mu_{\phi_{j}}^{j} \lambda^{j}}{\left(\mu^{j} \lambda^{j}-1\right)^{2}} b_{j}<0 \\
w_{\chi_{j}}^{j}=-\frac{\mu_{\chi_{j}}^{j} \lambda^{j}}{\left(\mu^{j} \lambda^{j}-1\right)^{2}} b_{j}>0 & w_{b_{j}}^{j}=\frac{\mu^{j} \lambda^{j}}{\mu^{j} \lambda^{j}-1}>0 .
\end{array}
$$

The sign of $w_{b_{j}}^{j}$ follows from the fact that $\mu^{j} \lambda^{j}-1>0$ must hold, as stated above. Since $w_{u_{j}}^{j}<0$, the wage-setting curve has a negative slope in real wage-unemployment space.

\subsection{Aggregate output and its impact on labor demand}

From eq. (6) it is obvious that labor demand in every country depends on aggregate output, which itself is an endogenous variable. Since national prices $p_{j}$ (in terms of the aggregate good) may differ, aggregate output has to be written as $Y=p_{A} Y_{A}+p_{B} Y_{B}$. Taking account of the inverse demand functions (5), the production functions at the national level, $Y_{j}=N_{j}^{\alpha} K_{j}^{1-\alpha}$, and the relationship $N_{j}=\left(1-u_{j}\right) L, j=A, B$, one gets:

$$
Y=y\left(u_{A}, u_{B}\right)=2^{\frac{\kappa-1}{\kappa}} L^{\alpha}\left[\left(1-u_{A}\right)^{\alpha \kappa} K_{A}^{(1-\alpha) \kappa}+\left(1-u_{B}\right)^{\alpha \kappa} K_{B}^{(1-\alpha) \kappa}\right]^{\frac{1}{\kappa}}
$$

with

$$
y_{u_{j}}=-\alpha\left[\left(1-u_{j}\right)\right]^{-1} Y_{j}^{\kappa}(Y / 2)^{1-\kappa}<0 \quad j=A, B
$$

According to eq. (17) aggregate output is a negative function of both unemployment rates. This has to be taken into account in the inverse labor demand equations of both countries, hence eq. (7) is written as

$$
w_{j}=n^{j}\left(u_{j}, y\left(u_{A}, u_{B}\right)\right) \quad n_{u_{j}}^{j}>0, \quad n_{Y}^{j}>0, \quad y_{u_{j}}<0, \quad j=A, B .
$$

The slope of the labor demand curve in real wage-unemployment space is given by

$$
n_{u_{j}}^{j}+n_{Y}^{j} y_{u_{j}}=\frac{w_{j}}{1-u_{j}}\left[(1-\alpha \kappa)-\alpha(1-\kappa) 2^{\kappa-1}\left(\frac{Y_{j}}{Y}\right)^{\kappa}\right] \quad j=A, B .
$$

To determine the sign of the terms in brackets, it has to be noted that with $\alpha<1$ it holds that $1-\alpha \kappa>\alpha(1-\kappa)$. Since $2^{\kappa-1}<1$ and $\left(Y_{j} / Y\right)^{\kappa}<1$, it follows unambiguously that 
$n_{u_{j}}^{j}+n_{Y}^{j} y_{u_{j}}>0$. This means that the labor demand curves of both countries are sloping upwards in real wage-unemployment space.

As a crucial feature of the model, labor demand of every country also depends on the unemployment rate of the other country via its impact on aggregate output. Since $n_{Y}^{j} y_{u_{i}}<0$ (for $i \neq j, i, j=A, B$ ), the labor demand curve shifts downward if unemployment in the neighboring country increases.

\section{Labor-market shocks in the closed economy}

Before analyzing the macroeconomic consequences of labor-market shocks in a two-country world, it is useful to consider the closed economy as a benchmark case. If countries A and $\mathrm{B}$ are identical in every respect, i.e. also with regard to labor-market institutions, the model in principle describes a closed economy with $\mathrm{F}$ firms and $2 L$ households. In this case all real wages are identical, hence $w_{i j}=w_{j}=w$. Furthermore it holds that $N_{j}=N / 2$ and $K_{j}=K / 2$ for $j=A, B$ and $Y=N^{\alpha} K^{1-\alpha}$, where $Y, N$ and $K$ are the aggregate variables for the closed economy. The wage-setting equations are obtained from eq. (15) or eq. (16) by simply omitting the index $j$. The (inverse) labor-demand function in eq. (7) can now be written as

$$
w=n(u)=\alpha \kappa\left(\frac{K}{(1-u) 2 L}\right)^{1-\alpha}, \quad \frac{\partial n}{\partial u} \equiv n_{u}=\frac{1-\alpha}{1-u} n(u)>0 .
$$

It must be stressed that in the closed economy the aggregate labor demand equation solely describes a relationship between real wages and employment (or unemployment). In other words, there is no room for aggregate output playing an "autonomous" role besides employment in the labor demand equation. This is in contrast to the two-country framework, where aggregate output depends on employment in both countries and labor demand is therefore influenced by employment (or unemployment) of the other country as well.

For the comparative-static analysis we focus on the special cases of the pure Bismarckian or Beveridgean unemployment compensation system. In the case of earnings-related benefits (ERB) the unemployment rate is determined by the closed-economy version of 
eq. (15). The real wage is then derived from eq. (21). On the other hand, with flatrate benefits $(\mathrm{FRB})$ the wage-setting equation corresponds to the closed-economy version of eq. (16). Unemployment and real wages are then simultaneously determined by the interplay of this wage-setting equation and the inverse labor-demand function (21).

As an example, we now consider the consequences of an increase in labor union power $\chi$, which can be summarized as

$$
\left.\frac{\partial u}{\partial \chi}\right|_{\mathrm{ERB}}=u_{\chi}=\frac{-\lambda \mu_{\chi}}{\mu \lambda_{u}}>\left.0 \quad \frac{\partial u}{\partial \chi}\right|_{\mathrm{FRB}}=\frac{w_{\chi}}{n_{u}-w_{u}}=\frac{-\lambda \mu_{\chi}}{\mu \lambda_{u}+n_{u}(\mu \lambda-1)^{2} / b}>0
$$

and

$$
\left.\frac{\partial w}{\partial \chi}\right|_{\mathrm{ERB}}=n_{u} u_{\chi}>\left.0 \quad \frac{\partial w}{\partial \chi}\right|_{\mathrm{FRB}}=\frac{n_{u} w_{\chi}}{n_{u}-w_{u}}>0 .
$$

Since the second term in the denominator of $\left.(\partial u / \partial \chi)\right|_{F R B}$ is positive, the whole expression is smaller (in absolute terms) than the corresponding expression for $\left.(\partial u / \partial \chi)\right|_{E R B}$. It immediately follows that $\left.(\partial w / \partial \chi)\right|_{E R B}>\left.(\partial w / \partial \chi)\right|_{F R B}$. As a result, an increase in labor union power leads to a stronger increase in unemployment and real wages if unemployment benefits are earnings-related. The same qualitative results are obtained if a lower weight $\phi$ is assigned to employment in labor unions' preferences or if unemployment benefits (i.e. $b$ or $\rho$ ) are increased.

These results are illustrated in figure 1. In the earnings-related unemployment compensation system the wage-setting (WS) curve is vertical, whereas in the case of flat-rate benefits the WS curve is falling. The labor demand (LD) curve is identical in both cases. ${ }^{8}$ The initial equilibrium is given by the unemployment rate $u_{0}$ and the real wage $w_{0}$ (point A). A rise in labor union power leads to the same outward shift of the WS curves in both cases. As can be seen from figure 1, the resulting change in unemployment and real wages is greater with earnings-related benefits (point $B_{E}$ ) than with flat-rate benefits (point $\mathrm{B}_{F}$ ). The intuition behind this difference is that in an earnings-related unemployment compensation system the expected alternative income $z$ will increase more than in

\footnotetext{
${ }^{8}$ The WS and LD curves are thought to be linear approximations of the respective non-linear relationships.
} 


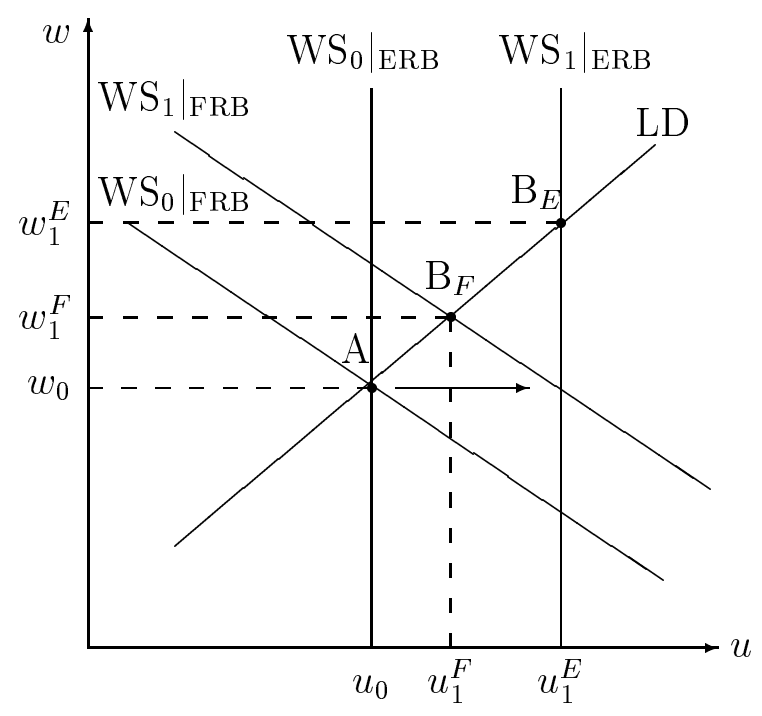

Figure 1: The consequences of an adverse labor market shock in the closed economy dependent on the type of unemployment compensation system

a flat-rate system because benefits are a function of the (rising) real wage. This leads cet. par. to higher wage pressure on the firm level.

It can be concluded that in the closed economy the variability of unemployment and real wages in response to labor market shocks is greater with earnings-related than with flatrate benefits. This implies that in the face of adverse labor market shocks the employment performance of the Bismarckian unemployment compensation system is less favorable than that of the Beveridgean system. However, if labor market reforms are undertaken, which are aimed at reducing unemployment (for instance by reducing labor union power), the resulting decline in unemployment is cet. par. stronger with earnings-related benefits.

\section{Idiosyncratic labor-market shocks in a two-country world}

Now we will scrutinize whether the closed-economy results derived in the last section are also valid for the open economy. In the two-country framework introduced in section 2 , 
the labor demand of one country is influenced by the unemployment rate of the other country via its impact on aggregate output. The analysis of the domestic consequences of a labor market shock in country A must therefore take account of the reaction to this shock in country B. This in turn is influenced by the unemployment compensation system prevailing in country B. Hence, depending on the type of unemployment benefits in each country, four model variants can be distinguished. The analysis also enables us to answer the question of how the unemployment compensation system influences spillover effects of labor market shocks originating from abroad. To do so, we only have to emphasize the results for country $\mathrm{B}$ in the following analysis.

In all model variants the two-country equilibrium can be described by the following system of four equations consisting of two inverse labor-demand functions (a) and two wagesetting equations (either (b1) or (b2)).

\section{a) Labor demand}

$$
w_{j}=n^{j}\left(u_{j}, y\left(u_{A}, u_{B}\right)\right), \quad n_{u_{j}}^{j}>0, \quad n_{Y}^{j}>0, \quad y_{u_{j}}<0, \quad j=A, B
$$

\section{b1) Wage setting with earnings-related benefits:}

$$
u_{j}=u^{j}\left(\phi_{j}, \chi_{j}, \rho_{j}\right), \quad u_{\phi_{j}}^{j}<0, \quad u_{\chi_{j}}^{j}>0, \quad u_{\rho_{j}}^{j}>0, \quad j=A, B
$$

\section{b2) Wage setting with flat-rate benefits:}

$$
w_{j}=w^{j}\left(u_{j}, \phi_{j}, \chi_{j}, b_{j}\right), \quad w_{u_{j}}^{j}<0, \quad w_{\phi_{j}}^{j}<0, \quad w_{\chi_{j}}^{j}>0, \quad w_{b_{j}}^{j}>0, \quad j=A, B
$$

The system contains the endogenous variables $w_{j}$ and $u_{j}(j=A, B)$. We focus on the consequences of an adverse labor market shock in country A which, for example, is caused by an increase in labor union power, $\chi_{A}$. However, one should bear in mind that the qualitative results derived below also apply to the case where labor union's preferences for employment, $\phi_{A}$, decline or the generosity of unemployment benefits $\left(\rho_{A}\right.$ or $\left.b_{A}\right)$ is increased. Of course, with the following analysis conclusions about positive labor market shocks are also possible. Such shocks might be caused by labor market reforms in country $A$ which, for instance, lead to reduced labor union power or lower unemployment benefits in that country. 
Case I: Earnings-related benefits in both countries. In this case the model can be solved recursively. The unemployment rates of both countries are determined by eq. (15). The solution for real wages is then obtained from eq. (19). Hence

$$
\left.\frac{\partial u_{A}}{\partial \chi_{A}}\right|_{\text {Case I }}=u_{\chi_{A}}^{A}>\left.0 \quad \frac{\partial u_{B}}{\partial \chi_{A}}\right|_{\text {Case I }}=0
$$

and

$$
\left.\frac{\partial w_{A}}{\partial \chi_{A}}\right|_{\text {Case I }}=\left(n_{u_{A}}^{A}+n_{Y}^{A} y_{u_{A}}\right) u_{\chi_{A}}^{A}>\left.0 \quad \frac{\partial w_{B}}{\partial \chi_{A}}\right|_{\text {Case I }}=n_{Y}^{B} y_{u_{A}} u_{\chi_{A}}^{A}<0 .
$$

The positive sign for $\partial w_{A} / \partial \chi_{A}$ follows from the discussion in section 2.4, where it has been shown that the slope of the labor demand curve is positive .

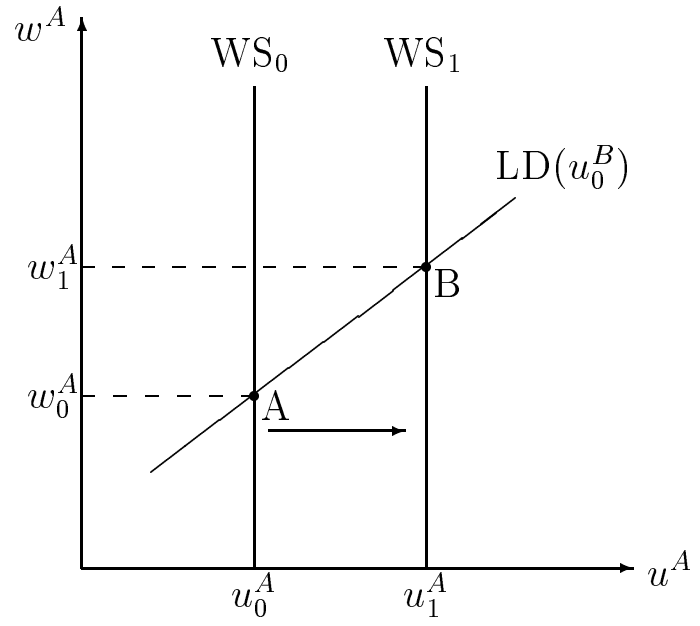

(a) Earnings-related benefits in country A

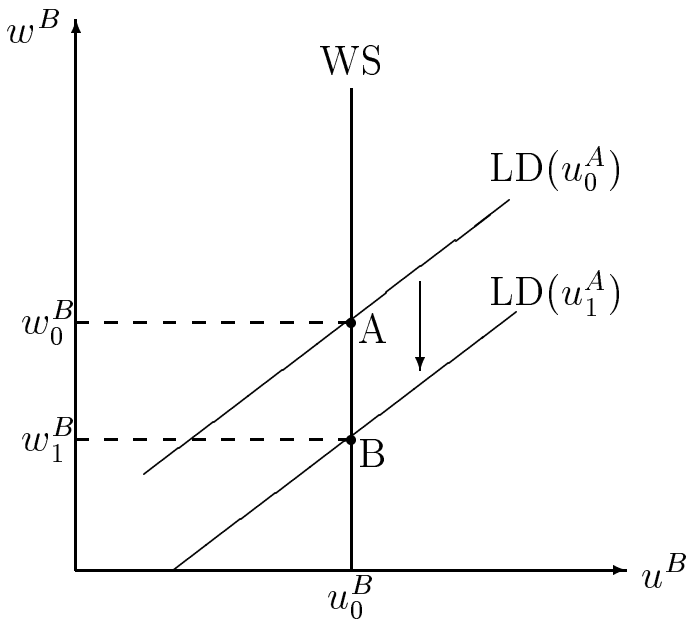

(b) Earnings-related benefits in country B

Figure 2: The consequences of an increase in wage pressure in country A in case I

In figure 2 the consequences of an adverse labor market shock in country A are depicted. Earnings-related unemployment benefits imply vertical wage-setting curves in both countries. Rising wage pressure in country A shifts the respective WS curve to the right, leading to higher unemployment and higher real wages in this country. Due to the rise in unemployment aggregate output declines, thereby shifting the labor demand curve of country B downwards. As a result, the employees in country B experience a real wage decline, but employment remains unchanged. 


\section{Case II: Flat-rate benefits in country A and earnings-related benefits in coun-}

try B. To determine the change in unemployment and real wages in country A, the labor-demand equation (19) and the wage-setting equation (16) must be considered simultaneously. As in case I, in country B only real wages are affected by the shock in country A. The respective results are:

$$
\left.\frac{\partial u_{A}}{\partial \chi_{A}}\right|_{\text {Case II }}=\frac{w_{\chi_{A}}^{A}}{\left(n_{u_{A}}^{A}+n_{Y}^{A} y_{u_{A}}\right)-w_{u_{A}}^{A}}>\left.0 \quad \frac{\partial u_{B}}{\partial \chi_{A}}\right|_{\text {Case II }}=0
$$

and

$$
\left.\frac{\partial w_{A}}{\partial \chi_{A}}\right|_{\text {Case II }}=\frac{w_{\chi_{A}}^{A}\left(n_{u_{A}}^{A}+n_{Y}^{A} y_{u_{A}}\right)}{\left(n_{u_{A}}^{A}+n_{Y}^{A} y_{u_{A}}\right)-w_{u_{A}}^{A}}>\left.0 \quad \frac{\partial w_{B}}{\partial \chi_{A}}\right|_{\text {Case II }}=\frac{n_{Y}^{B} y_{u_{A}} w_{\chi_{A}}^{A}}{\left(n_{u_{A}}^{A}+n_{Y}^{A} y_{u_{A}}\right)-w_{u_{A}}^{A}}<0 .
$$

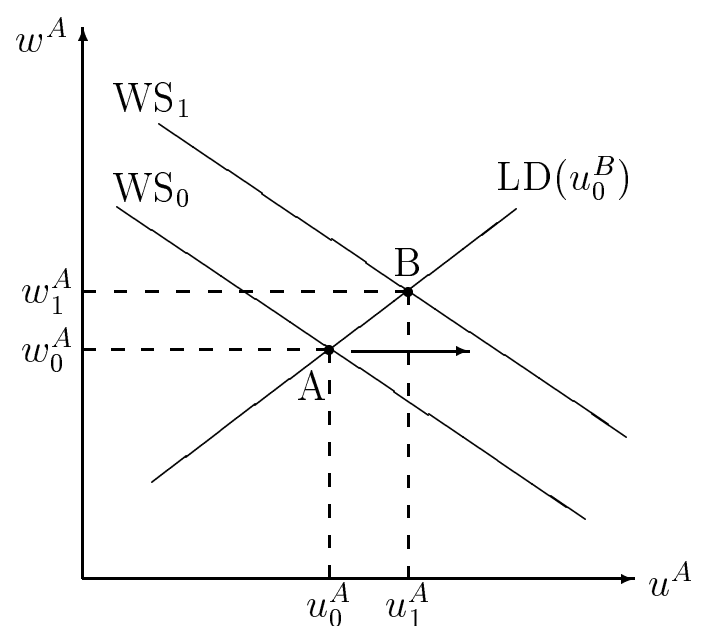

(a) Flat-rate benefits in country A

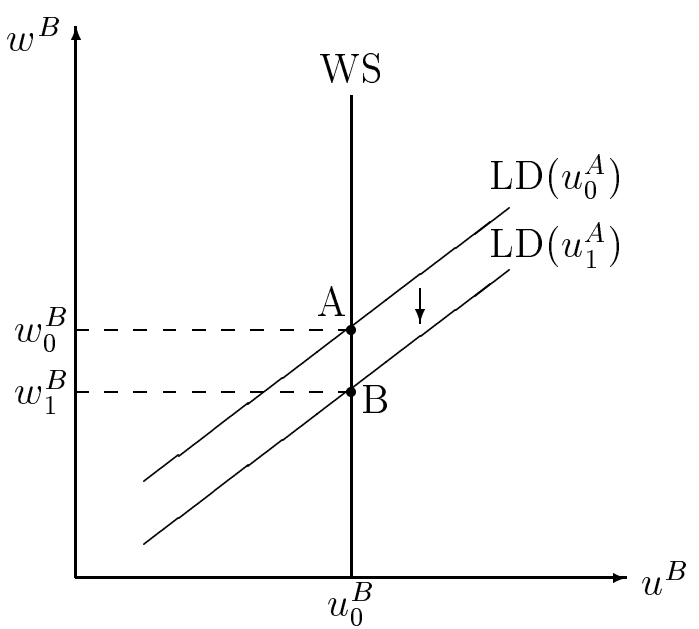

(b) Earnings-related benefits in country B

Figure 3: The consequences of an increase in wage pressure in country A in case II

Figure 3 illustrates the results. Due to the adverse labor market shock the WS curve of country A moves to the right, leading to a new equilibrium at point B. The increase in unemployment in country A shifts the labor demand curve of the other country downwards. With a vertical wage-setting curve in country B only the real wage level but not employment is adversely affected by the shock originating from abroad. Comparing cases I and II, it can be analytically shown that in country A the increase in unemployment and real 
wages is greater with earnings-related benefits (ERB) than with flat-rate benefits (FRB). The computations are analogous to the discussion for the closed economy. The conclusion is also evident from a comparison of figures 2 and 3 if it is taken into account that in both cases the WS curves are horizontally shifting by the same amount:

$$
\left.\frac{\mathrm{d} u_{A}}{\mathrm{~d} \chi_{A}}\right|_{\mathrm{d} w_{A}=0} ^{\mathrm{WS}_{\mathrm{ERB}}}=u_{\chi_{A}}^{A}=-\frac{\lambda^{A} \mu_{\chi_{A}}^{A}}{\mu^{A} \lambda_{u_{A}}^{A}}=-\frac{w_{\chi_{A}}^{A}}{w_{u_{A}}^{A}}=\left.\frac{\mathrm{d} u_{A}}{\mathrm{~d} \chi_{A}}\right|_{\mathrm{d} w_{A}=0} ^{\mathrm{WS}_{\mathrm{FRB}}} .
$$

Since the decline in aggregate output is greater in the first variant of the model, the downward movement of the labor demand curve in country B is stronger in case I. Hence it can be concluded that the decline in real wages in country B is more pronounced if country A has earnings-related unemployment benefits.

\section{Case III: Earnings-related benefits in country A and flat-rate benefits in coun-}

try B. In this case the change in unemployment in country A is obtained from the wagesetting equation (15). With this solution the change in real wages and unemployment in country B can be obtained from the equation system (16) and (19). Taking account of the change in $u_{A}$ and $u_{B}$, finally from eq. (19) the change in real wages in country A can be computed. The results are

$$
\begin{aligned}
&\left.\frac{\partial u_{A}}{\partial \chi_{A}}\right|_{\text {Case III }}=u_{\chi_{A}}^{A}>\left.0 \quad \frac{\partial u_{B}}{\partial \chi_{A}}\right|_{\text {Case III }}=-\frac{n_{Y}^{B} y_{u_{A}} u_{\chi_{A}}^{A}}{\left(n_{u_{B}}^{B}+n_{Y}^{B} y_{u_{B}}\right)-w_{u_{B}}^{B}}>0 \\
&\left.\frac{\partial w_{A}}{\partial \chi_{A}}\right|_{\text {Case III }}=\frac{\left[\left(n_{u_{A}}^{A}+n_{Y}^{A} y_{u_{A}}\right)\left(n_{u_{B}}^{B}-w_{u_{B}}^{B}\right)+n_{u_{A}}^{A} n_{Y}^{B} y_{u_{B}}\right] u_{\chi_{A}}^{A}}{\left(n_{u_{B}}^{B}+n_{Y}^{B} y_{u_{B}}\right)-w_{u_{B}}^{B}}>0 \\
&\left.\frac{\partial w_{B}}{\partial \chi_{A}}\right|_{\text {Case III }}=-\frac{w_{u_{B}}^{B} n_{Y}^{B} y_{u_{A}} u_{\chi_{A}}^{A}}{\left(n_{u_{B}}^{B}+n_{Y}^{B} y_{u_{B}}\right)-w_{u_{B}}^{B}}<0 .
\end{aligned}
$$

For the determination of the sign of $\partial w_{A} / \partial \chi_{A}$ it has been taken into account that due to eqs. (8) and (18) it holds that

$$
\begin{aligned}
n_{u_{B}}^{B}\left(n_{u_{A}}^{A}+n_{Y}^{A} y_{u_{A}}\right)+n_{u_{A}}^{A} n_{Y}^{B} y_{u_{B}} & =n_{u_{A}}^{A} n_{u_{B}}^{B}\left(1+\frac{n_{Y}^{A} y_{u_{A}}}{n_{u_{A}}^{A}}+\frac{n_{Y}^{B} y_{u_{B}}}{n_{u_{B}}^{B}}\right) \\
& =n_{u_{A}}^{A} n_{u_{B}}^{B}\left(1-\frac{\alpha(1-\kappa)}{1-\alpha \kappa}\right)>0 .
\end{aligned}
$$

For the last step one has to take account of the definition of $Y$ and the fact that $1-\alpha \kappa>\alpha(1-\kappa)$. From figure 4 the differences to the preceding model variants become 
evident. The adverse labor market shock in country A shifts the WS curve to the right, implying higher real wages and unemployment in that country. However, the accompanying downward shift of the labor demand curve in country B not only implies lower real wages but also higher unemployment, since with flat-rate benefits the WS curve is downward sloping. The increase in unemployment in country B reinforces the decline in aggregate output, provoking a repercussion effect which shifts the labor demand curve of country A downwards. The final equilibrium in both countries is represented by point $\mathrm{C}$.

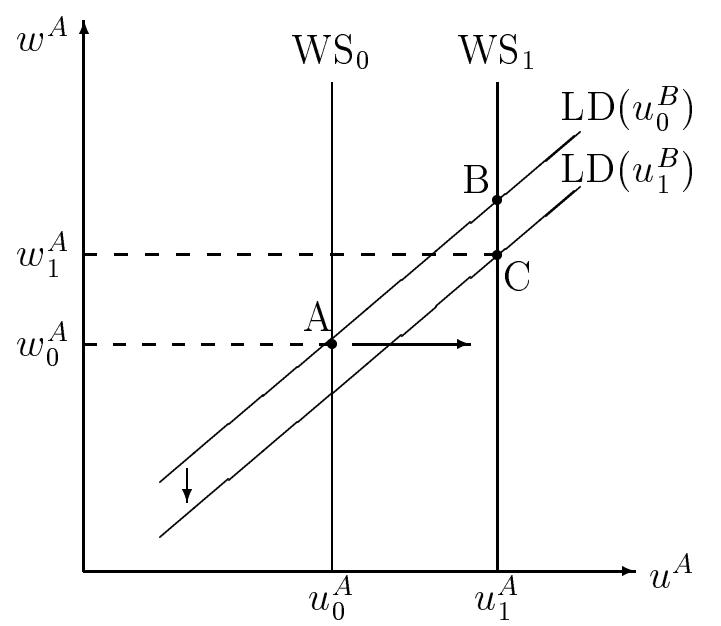

(a) Earnings-related benefits in coun-

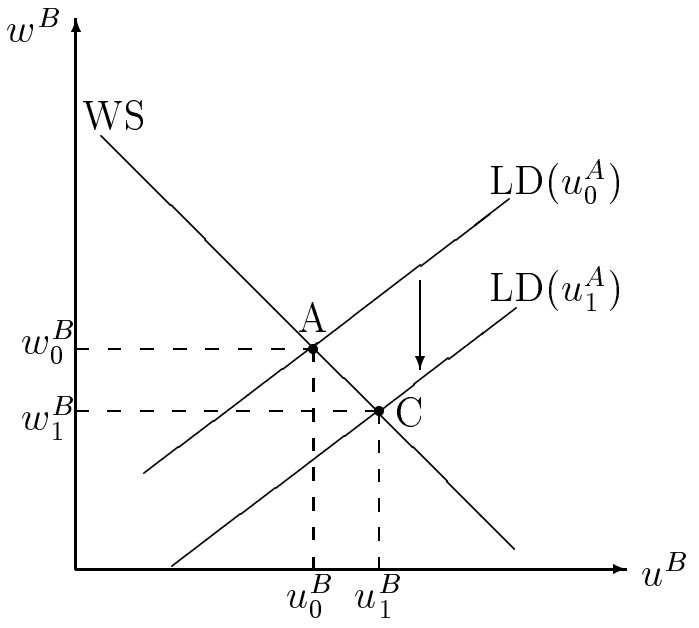

(b) Flat-rate benefits in country B try A

Figure 4: The consequences of an increase in wage pressure in country A in case III

The results can be easily compared with the respective figure for case I, where in both countries earnings-related benefits are paid. It is evident that in both model variants country A experiences the same increase in unemployment. However, with flat-rate benefits in country B the further decline in aggregate output dampens the real wage increase in country A. In country B an earnings-related unemployment compensation system partly neutralizes adverse labor market shocks originating from abroad, since only real wages but not employment are affected. 
Case IV: Flat-rate benefits in both countries. In this case unemployment rates and real wages of both countries are determined simultaneously. By equating eqs. (16) and (19) the system can be reduced to a two-equation system, which determines unemployment in both countries. The effects of a rise in labor union power in country A can then be derived from

$$
\left(\begin{array}{c}
\partial u_{A} / \partial \chi_{A} \\
\partial u_{B} / \partial \chi_{A}
\end{array}\right)=\mathbf{J}^{-1}\left(\begin{array}{c}
w_{\chi_{A}}^{A} \\
0
\end{array}\right), \quad \mathbf{J}=\left(\begin{array}{cc}
n_{u_{A}}^{A}+n_{Y}^{A} y_{u_{A}}-w_{u_{A}}^{A} & n_{Y}^{A} y_{u_{B}} \\
n_{Y}^{B} y_{u_{A}} & n_{u_{B}}^{B}+n_{Y}^{B} y_{u_{B}}-w_{u_{B}}^{B}
\end{array}\right) .
$$

To determine the sign of $|\mathbf{J}|$, eq. (23) must be taken into account. It is then easily seen that

$$
\begin{aligned}
|\mathbf{J}|= & -\left(n_{u_{A}}^{A}+n_{Y}^{A} y_{u_{A}}\right) w_{u_{B}}^{B}-\left(n_{u_{B}}^{B}+n_{Y}^{B} y_{u_{B}}\right) w_{u_{A}}^{A}+w_{u_{A}}^{A} w_{u_{B}}^{B} \\
& +n_{u_{B}}^{B}\left(n_{u_{A}}^{A}+n_{Y}^{A} y_{u_{A}}\right)+n_{u_{A}}^{A} n_{Y}^{B} y_{u_{B}}>0 .
\end{aligned}
$$

This leads to

$$
\begin{aligned}
\left.\frac{\partial u_{A}}{\partial \chi_{A}}\right|_{\text {Case IV }} & =\left.\frac{\left(n_{u_{B}}^{B}+n_{Y}^{B} y_{u_{B}}-w_{u_{B}}^{B}\right) w_{\chi_{A}}^{A}>0}{|\mathbf{J}|} \quad \frac{\partial u_{B}}{\partial \chi_{A}}\right|_{\text {Case IV }}=-\frac{n_{Y}^{B} y_{u_{A}} w_{\chi_{A}}^{A}}{|\mathbf{J}|} 00 \\
\left.\frac{\partial w_{A}}{\partial \chi_{A}}\right|_{\text {Case IV }} & =\frac{\left[\left(n_{u_{A}}^{A}+n_{Y}^{A} y_{u_{A}}\right)\left(n_{u_{B}}^{B}-w_{u_{B}}^{B}\right)+n_{u_{A}}^{A} n_{Y}^{B} y_{u_{B}}\right] w_{\chi_{A}}^{A}}{|\mathbf{J}|}>0 \\
\left.\frac{\partial w_{B}}{\partial \chi_{A}}\right|_{\text {Case IV }} & =-\frac{w_{u_{B}}^{B} n_{Y}^{B} y_{u_{A}} u_{\chi_{A}}^{A}}{|\mathbf{J}|}<0 .
\end{aligned}
$$

The sign of $\partial w_{A} / \partial \chi_{A}$ is determined along the lines outlined for the third model variant (see eq.(23)). The results are illustrated in figure 5. The increase in wage pressure in country A leads to an increase in unemployment in both countries. In contrast to case III the repercussion effect from country B now reinforces the increase in unemployment in country A due to the downward-sloping wage-setting curve. The new equilibrium in both countries is represented by point $\mathrm{C}$. The increase in unemployment is accompanied by rising real wages in country A and declining real wages in country B. 


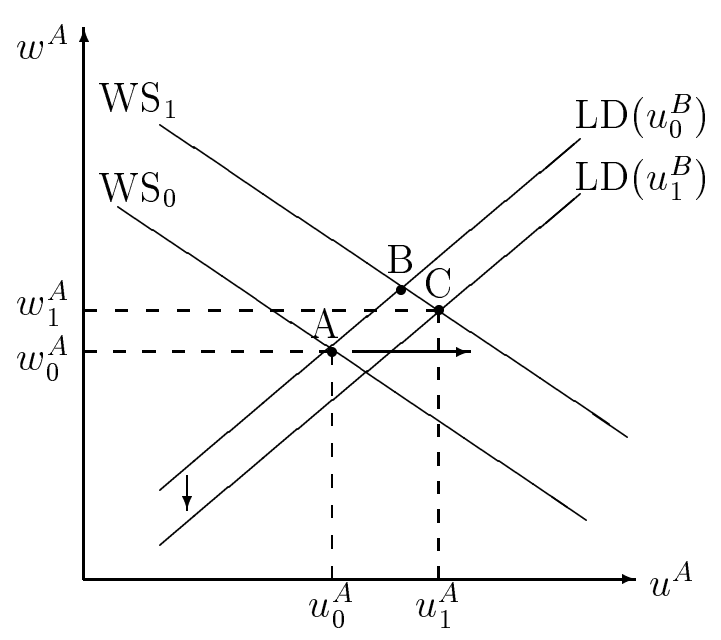

(a) Flat-rate benefits in country A

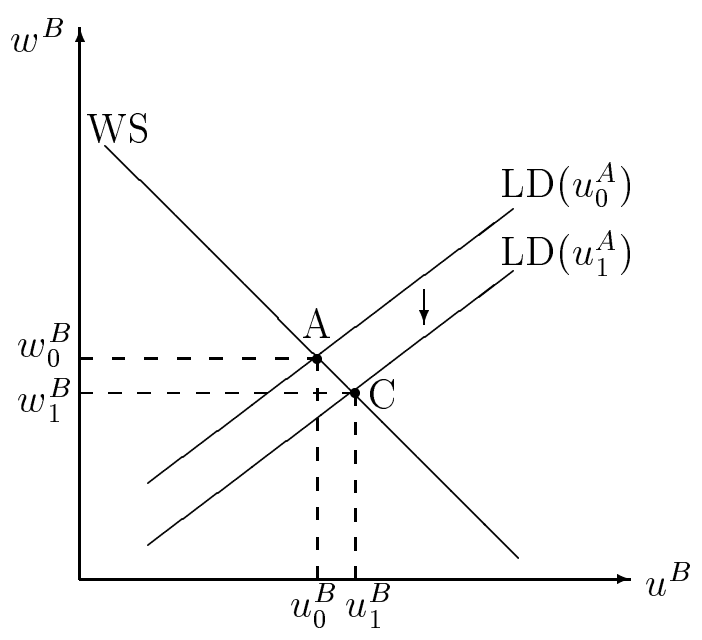

(b) Flat-rate benefits in country B

Figure 5: The consequences of an increase in wage pressure in country A in case IV

\section{Comparison of results and model extensions}

In this section we compare the comparative-static results for the four model variants with respect to employment and real wage effects. The evaluation is facilitated by juxtaposing the respective figures. ${ }^{9}$ It is then easy to see that with respect to unemployment the ranking is unambiguous for both countries (see table 1). Country A experiences the strongest increase in unemployment in cases I and III and the weakest increase in case II. For country B the highest rise in unemployment occurs in case III, whereas in cases I and II unemployment does not change at all. However, with regard to real wages the results are less clear-cut. For country B it can be concluded that

$$
\left.\left.\left|\frac{\partial w^{B}}{\partial \chi_{A}}\right|_{\mathrm{I}}|>| \frac{\partial w^{B}}{\partial \chi_{A}}\right|_{\mathrm{III}}|>| \frac{\partial w^{B}}{\partial \chi_{A}}\right|_{\mathrm{IV}} \mid \quad \text { and }\left.\quad\left|\frac{\partial w^{B}}{\partial \chi_{A}}\right|_{\mathrm{I}}|>| \frac{\partial w^{B}}{\partial \chi_{A}}\right|_{\mathrm{II}} \mid .
$$

If the decline in country B's real wages in case II is greater than in case III (in absolute values), no further comparisons are necessary to get an unambiguous ranking of real wage

\footnotetext{
${ }^{9}$ For the comparison one must bear in mind that the rightward shift of the WS curve in country A is the same in all cases and the downward movement of the labor demand curve in country B depends on the increase in unemployment in country A.
} 
Table 1

Results of the comparative-static analysis

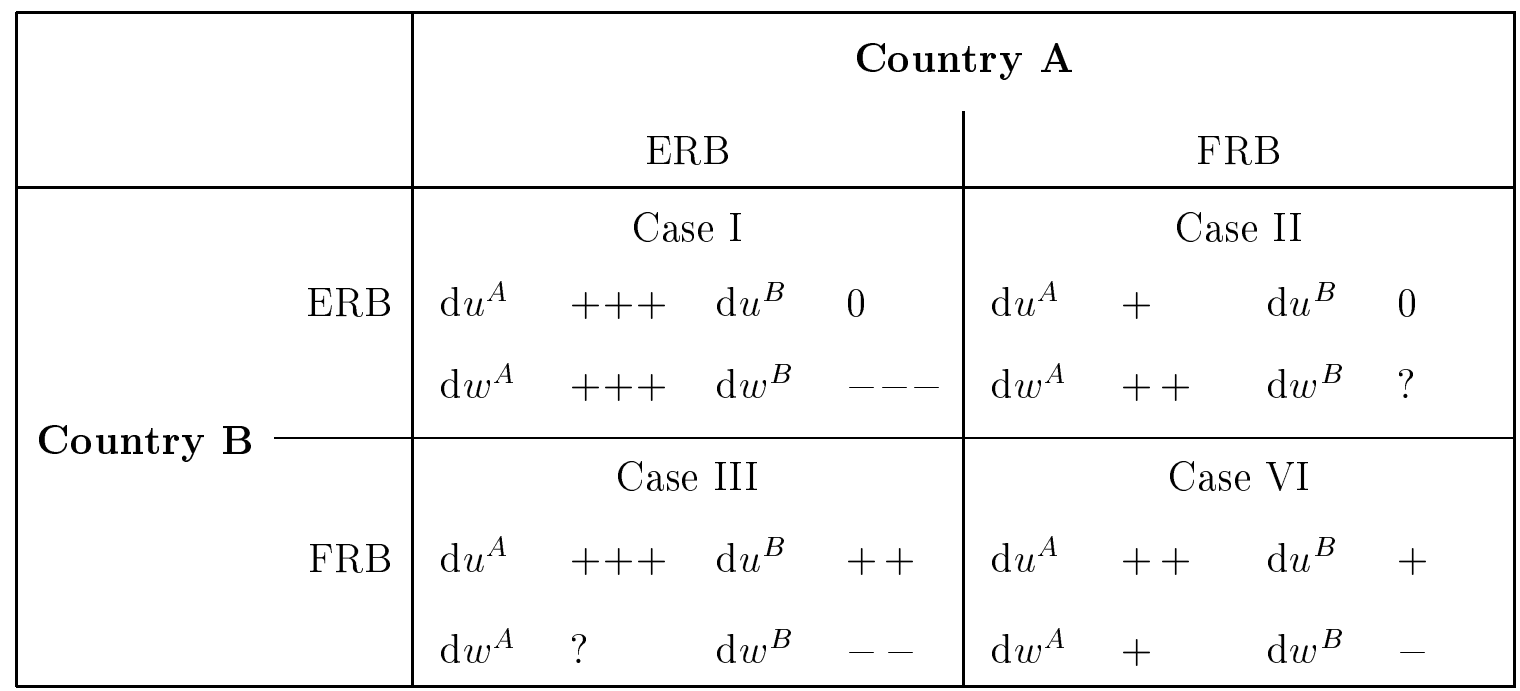

Note: In all cases it is assumed that an adverse labor market shock occurs in country A. ERB: earningsrelated benefits; FRB: flat-rate benefits;,,++++++ : very strong increase, strong increase and increase, respectively; ---, - -, -: very strong decline, strong decline and decline, respectively; 0: no change; ? means that an unambiguous ranking relative to all other cases is not possible. However, it is known that $\mathrm{d} w_{I I I}^{A}>0$ and $\mathrm{d} w_{I I}^{B}<0$.

outcomes. This condition requires that

$$
-\frac{n_{Y}^{B} y_{u_{A}} w_{\chi_{A}}^{A}}{\left(n_{u_{A}}^{A}+n_{Y}^{A} y_{u_{A}}\right)-w_{u_{A}}^{A}}>\frac{w_{u_{B}}^{B} n_{Y}^{B} y_{u_{A}} u_{\chi_{A}}^{A}}{\left(n_{u_{B}}^{B}+n_{Y}^{B} y_{u_{B}}\right)-w_{u_{B}}^{B}} .
$$

Due to eq. (22) $u_{\chi_{A}}^{A}$ can be substituted by $-w_{\chi_{A}}^{A} / w_{u_{A}}^{A}$. Hence, the real wage decline in variant II is greater than in variant III if

$$
\frac{w_{u_{A}}^{A}}{w_{u_{B}}^{B}}>\frac{n_{u_{A}}^{A}+n_{Y}^{A} n_{y_{A}}^{A}}{n_{u_{B}}^{B}+n_{Y}^{B} y_{u_{B}}}
$$

Condition (25) can be easily interpreted. The steeper the wage-setting curve and the flatter the labor demand curve in country $\mathrm{A}$, the more pronounced is the increase in $u_{A}$ and hence the decline in $w_{B}$ in case II. The flatter the wage-setting curve and the steeper the labor demand curve in country $\mathrm{B}$, the weaker is the real wage decline in that country in variant III.

With respect to the change in real wages in country $\mathrm{A}$ it can be concluded that

$$
\left.\frac{\partial w^{A}}{\partial \chi_{A}}\right|_{\mathrm{I}}>\left.\frac{\partial w^{A}}{\partial \chi_{A}}\right|_{\mathrm{II}}>\left.\frac{\partial w^{A}}{\partial \chi_{A}}\right|_{\mathrm{IV}} \quad \text { and }\left.\quad \frac{\partial w^{A}}{\partial \chi_{A}}\right|_{\mathrm{I}}>\left.\frac{\partial w^{A}}{\partial \chi_{A}}\right|_{\mathrm{III}}
$$


A complete ranking of real wage outcomes would, for instance, be possible if $\left.\mathrm{d} w^{A}\right|_{I I I}>$ $\left.\mathrm{d} w_{A}\right|_{I I}$. Analogous to the above discussion it can be shown that a sufficient condition for this is that the inequality sign in eq. (25) is reversed. However, if condition (25) holds, it is possible that $\left.\mathrm{d} w^{A}\right|_{I I I}<\left.\mathrm{d} w_{A}\right|_{I I I}$. In this case an additional comparison of $\left.\mathrm{d} w^{A}\right|_{I I I}$ and $\left.\mathrm{d} w^{A}\right|_{I V}$ would be necessary.

Up until now we only considered pure earnings-related or flat-rate unemployment compensation systems. However, most European countries have a two-tier system where an unemployed person either receives earnings-related or flat-rate unemployment benefits depending on the duration of unemployment, eligibility criteria and so on. The Bismarckian and Beveridgean systems analyzed above can also be interpreted as useful benchmark cases from which the following results can be derived for a two-tier unemployment compensation system.

It has been demonstrated that an earnings-related system leads to greater employment effects than a flat-rate system in the country where the labor market shock originates, whereas the reverse is true for the other country which is affected by the shock spillover. The graphical analysis made clear that the slope of the wage-setting curve is of central relevance for this result. Since earnings-related benefits are usually at least as high as flat-rate benefits in two-tier unemployment compensation systems, it follows from the discussion in appendix A.2 that a country with a two-tier system has cet. par. a steeper wage-setting curve than a country with a flat-rate system, but the WS curve will not be vertical as with earnings-related benefits. Since a two-tier unemployment compensation system lies somewhere in between the Bismarckian and Beveridgean system, the employment effects of shocks also lie in between the effects derived above. As a consequence, the employment effect of a labor market shock will be weaker than it would be under a Bismarckian (Beveridgean) system for country A (B). On the other hand, it will be stronger than the employment effect that arises if country A (B) has a flat-rate (earningsrelated) unemployment compensation system. These results can be generalized, since the slope of the wage-setting curve depends on the percentage $\gamma_{j}$ of unemployed receiving earnings-related benefits. A higher $\gamma_{j}$ means that the two-tier system comes closer to a Bismarckian system. In appendix A.2 it is shown that the WS curve will become steeper 
if $\gamma_{j}$ increases. Hence, with rising $\gamma_{j}$ the employment effect for country A (B) will become greater (smaller).

As a final remark we would like to point out that we have checked the robustness of our results by modifying some of the model's assumptions. In Beissinger, Buesse (2000) a model variant is considered where the production technology is described by a CES instead of a Cobb-Douglas function. ${ }^{10}$ It turns out that in this case the wage-setting curve in combination with earnings-related benefits is no longer vertical but downward sloping. ${ }^{11}$ Moreover, the increase in unemployment in country A then shifts both the labor demand and the wage-setting curve downwards in country B. However, our qualitative results are not affected by these modifications. Consider cases I or II of our model, where an earnings-related unemployment compensation system prevails in country B. It can be shown that in this case the downward shift of the WS and LD curves in country B is of equal size, which again leads to the result that real wages decline but unemployment remains unaffected in that country. If in country B benefits are paid as flat-rate transfers (as in cases III and IV), the downward shift of the WS curve is less pronounced than the shift of the LD curve, which implies that real wages decline and unemployment increases. In our analysis we have assumed that unemployment benefits are financed by taxes on the fixed stock of capital. If it is instead assumed that benefits are financed by a proportional tax on wage income, the government budget constraint must be taken into account in the equation for the wage-setting curve. It is demonstrated in appendix A.1 that in the case with earnings-related benefits the wage-setting curve remains vertical. However, in the case with flat-rate benefits an additional condition is necessary to guarantee that the wage-setting curve is downward sloping in real wage-unemployment space. The reason is

\footnotetext{
${ }^{10}$ The focus of Beissinger, Buesse (2000) is on a critique of previous studies which did not take account of all comparative-static effects occurring in a two-country setting. Hence, the analysis differs from this paper. For instance, in Beissinger, Buesse (2000), no quantitative comparison of comparative-static outcomes and no comparison with closed economy results is performed. Furthermore, the analysis is restricted to "symmetric" model variants with a two-tier unemployment compensation system or with flat-rate benefits in both countries.

${ }^{11}$ For this result to hold it is sufficient that the elasticity of substitution between labor and capital is less than one.
} 
that higher unemployment also leads to higher income taxes, which cet. par. generates higher wage pressure. If the wage-setting curve is downward sloping, our results also remain valid in the case where benefits are financed by a tax on wage income.

\section{Summary and conclusions}

In this paper we discuss the consequences of labor market shocks for economies with either a Bismarckian (i.e. earnings-related) or Beveridgean (i.e. flat-rate) unemployment compensation system. For the analysis a two-country model with imperfect competition on goods and labor markets is developed. On the goods market monopolistic competition prevails, and the labor market outcome is influenced by wage bargains taking place between firms and labor unions. While the goods market is integrated, labor markets are separated since it is assumed that international mobility of labor is hindered by cultural and linguistic barriers. The labor market shocks considered are changes in the relative bargaining power of labor unions, the generosity of unemployment benefits or labor unions' preferences.

As a benchmark case the consequences of labor market shocks in the closed economy are examined first. This is a special variant of the model where both countries are united to a single economy with the same labor market institutions. It is shown that labor market shocks lead to a stronger change in unemployment if the unemployment compensation system is earnings-related. For the country where the shock occurs a similar result is obtained in the two-country framework, in which repercussion effects from the neighboring country have additionally to be taken into account. The two-country analysis also makes clear how the unemployment compensation system influences spillover effects of labor market shocks originating from abroad. It is shown that an earnings-related unemployment compensation system partly neutralizes such shocks, since only real wages but not employment are affected. In contrast, with flat-rate unemployment benefits both unemployment and real wages are influenced by labor market shocks stemming from abroad. Our results suggest that in the discussion about reforms of the unemployment compensation system the susceptibility to labor market shocks should also be taken into account. 
Suppose, for instance, that the government wants to implement an unemployment compensation system which minimizes employment fluctuations. The choice then depends on whether labor market shocks are expected to occur in the home country more frequently than abroad. If labor market shocks usually have their origin in the domestic economy, a flat-rate unemployment compensation system is more suitable to dampen employment fluctuations. However, if the economy is hit by labor market shocks stemming from abroad, an earnings-related unemployment compensation system should be chosen.

The assessment of both systems changes if the government expects that mainly positive labor market shocks occur in the future. For instance, if it is planned to reduce unemployment by labor market reforms, the employment gains would be stronger under an earnings-related unemployment compensation system. Other countries could profit from the reforms in the neighboring country in terms of employment if benefits were paid as flat-rate transfers.

\section{A Appendix}

\section{A.1 Analysis with proportional tax on wage income}

With a proportional tax rate $t_{j}$ on wages, the net wage $w_{i j}\left(1-t_{j}\right)$ enters labor unions' utility function (9). Instead of eq. (13) one then obtains

$$
w_{j}\left(1-t_{j}\right)=\mu^{j} \lambda^{j} s^{j} /\left(\mu^{j} \lambda^{j}-1\right) .
$$

Consider first the case with a pure earnings-related unemployment compensation system $\left(\gamma_{j}=1\right)$. If benefits are tied to net wages (as, for instance, in Germany), $s^{j}=\rho_{j} w_{j}(1-$ $\left.t_{j}\right) .{ }^{12}$ If this is inserted in eq. (13'), again eq. (15) and hence a vertical wage-setting curve is obtained. If benefits are tied to gross wages, $s^{j}=\rho_{j} w_{j}$. In this case instead of eq. (15) one obtains $\left(1-t_{j}-\rho_{j}\right) \mu^{j} \lambda^{j}-\left(1-t_{j}\right)=0$. An admissible solution requires $1-t_{j}-\rho_{j}>0$. To close the model the government budget constraint must explicitly be taken into account.

\footnotetext{
${ }^{12} \mathrm{~A}$ more detailed account of various institutional arrangements in the EU member states, concerning the taxation and price indexation of unemployment benefits as well as tax exemptions is found in Koskela, Schöb (1999).
} 
The tax rate is endogenously determined in such a way that the government budget $G B_{j}=t_{j} w_{j} N_{j}-\left(L-N_{j}\right) s^{j}$ is balanced. This leads to $t_{j}=\left(u_{j} s^{j}\right) /\left[\left(1-u_{j}\right) w_{j}\right]$. For $s^{j}=\rho_{j} w_{j}$ one gets $t_{j}=u_{j} \rho_{j} /\left(1-u_{j}\right)$. The solution for $t_{j}$ must be taken into account in the wage-setting equation. It then can immediately be seen that the unemployment rate is again determined by the wage-setting equation alone, i.e. the wage-setting curve is vertical.

With flat-rate benefits (i.e. $\left.\gamma_{j}=0\right), s_{j}=b_{j}$. If the solution for $t_{j}$ is inserted into eq. $\left(13^{\prime}\right)$, one obtains $w^{j}=\left(\mu^{j} \lambda^{j}-u_{j}\right) /\left(\left(\mu^{j} \lambda^{j}-1\right)\left(1-u_{j}\right)\right)$. If $w_{u_{j}}^{j}$ is computed, it can be seen that a somewhat more complicated condition is necessary to guarantee an (empirically confirmed) downward-sloping wage-setting curve. The reason is that due to the endogenous tax on wage income two opposing effects influence the wage-setting process. On the one hand, higher unemployment leads to a lower expected alternative income $z_{j}$ via its effect on $\lambda^{j}$, thereby lowering wage pressure. On the other hand, higher unemployment also necessitates tax increases at a given level of wages and benefits, thus inducing rising wage pressure. A simpler solution is obtained in a special variant of the model where $\lambda^{j}\left(u_{j}\right)=u_{j}$ in eq. (11). ${ }^{13}$ Then

$$
\frac{\partial w^{j}}{\partial u_{j}}=\frac{\left(\mu^{j}-1\right)\left(\mu^{j} u_{j}^{2}-1\right)}{\left(\mu^{j} u_{j}-1\right)^{2}\left(u_{j}-1\right)^{2}} .
$$

Additionally to the condition $\mu^{j} u_{j}>1$, which is necessary for $w_{j}>0$, a downwardsloping wage-setting curve requires $\mu^{j} u_{j}^{2}<1$. Taken together, it must be assumed that $u_{j}^{-1}<\mu_{j}<u_{j}^{-2}$. The analysis then leads to the same qualitative comparative-static results as outlined in the paper.

\section{A.2 The dependence of the slope of the WS curve on the share of earnings-related benefits}

In the two-tier system a percentage $\gamma_{j}$ of the unemployed persons receives earnings-related benefits. In this appendix it is scrutinized how the slope of the wage-setting curve changes

\footnotetext{
${ }^{13}$ This assumption is often made in the literature to simplify the analysis.
} 
if $\gamma_{j}$ rises. Due to eq. (13) the slope of the wage-setting curve can be written as ${ }^{14}$

$$
w_{u_{j}}^{j}=-\frac{\mu^{j} \lambda_{u_{j}}^{j} s^{j}}{\left[\mu^{j} \lambda^{j}\left(1-s_{w_{j}}^{j}\right)-1\right]\left[\mu^{j} \lambda^{j}-1\right]}<0 \quad \text { for } \gamma_{j}<1 .
$$

Note that with the definition of $s^{j}$ in eq. (12) $s_{w_{j}}^{j}=\gamma_{j} \rho_{j}$. The negative sign in eq. (A.2) follows from the fact that the expressions in brackets must be positive (see the condition after eq. (14)). If $\gamma_{j}$ rises, the slope of the wage-setting curve changes according to

$$
\frac{\partial^{2} w^{j}}{\partial u_{j} \partial \gamma_{j}}=-\frac{\mu^{j} \lambda_{u_{j}}^{j}\left\{s_{\gamma_{j}}^{j}\left[\mu^{j} \lambda^{j}\left(1-s_{w_{j}}^{j}\right)-1\right]+\mu^{j} \lambda^{j} s^{j} \frac{\partial^{2} s^{j}}{\partial w_{j} \partial \gamma_{j}}\right\}}{\left[\mu^{j} \lambda^{j}\left(1-s_{w_{j}}^{j}\right)-1\right]^{2}\left(\mu^{j} \lambda^{j}-1\right)} \quad \text { for } \gamma_{j}<1
$$

The term in brackets in the nominator is positive. Due to eq. (12) $\partial^{2} s^{j} /\left(\partial w_{j} \partial \gamma_{j}\right)=\rho_{j}>0$. Hence, the sign of the derivative in eq. (A.3) depends on $s_{\gamma_{j}}^{j}$, i.e. on the change in the level of average unemployment benefits due to an increase in the share of earnings-related benefits. With the definition of $s^{j}$ it follows that $s_{\gamma_{j}}^{j}=\rho_{j} w_{j}-b_{j}$. A sufficient condition for the wage-setting curve to become steeper if $\gamma_{j}$ increases is that $s_{\gamma_{j}}^{j} \geq 0$. This implies that earnings-related benefits are at least as high as flat-rate benefits, which is an empirically plausible condition. Since eq. (A.3) also holds at $\gamma_{j}=0$, it follows that the wage-setting curve under a two-tier unemployment compensation system is steeper than with flat-rate benefits. On the other hand, it is not vertical as in the case of a pure earnings-related unemployment compensation system.

\section{Literature}

Atkinson, A., Micklewright, J., 1991, Unemployment Compensation and Labor Market Transitions: A Critical Review, Journal of Economic Literature, 29, 1679-1727.

Beissinger, T., Buesse, O., 2000, Are Countries Profiting From Rising Wage Pressure Abroad?, University of Regensburg, mimeo.

Beissinger, T. and Egger, H., 2000, Some Pitfalls in Dynamic Wage Bargaining Models, University of Regensburg Discussion Paper No. 343.

Beveridge Report, 1942, Social Insurance and Allied Services, Cmd 6404, London: HMSO. Blanchard, O.J., Kiyotaki, N., 1987, Monopolistic Competition and the Effects of Aggregate Demand, American Economic Review, 77(4), 647-666.

Bräuninger, M., 2001, Unemployment Insurance, Wage Differentials and Unemployment, will appear in Finanzarchiv.

\footnotetext{
${ }^{14}$ Note that in the case of a pure earnings-related unemployment compensation system, i.e. $\gamma_{j}=1$, this derivative is not defined.
} 
Clasen, J., 1994, Paying the Jobless. A comparison of unemployment benefit policies in Great Britain and Germany. Aldershot: Avebury.

Cremer, H., Pestieau, P. 1998, Social insurance, majority voting and labor mobility, Journal of Public Economics, 68, 397-420.

Dixit, A., Stiglitz, J., 1977, Monopolistic Competition and Optimum Product Diversity, American Economic Review, 67(3), 297-308.

Goerke, L. 2000, Bismarck versus Beveridge. Flat- and Earnings-Related Unemployment Insurance in an Efficiency Wage Framework, Finanzarchiv, 57(3), 243-260.

Goerke, L., Madsen, J.B., 2000, Earnings-Related Unemployment Benefits and Unemployment in Unionised Economies, Discussion Paper.

Heer, B., Morgenstern, A., 2000, Indexation of Unemployment Benefits to Previous Earnings, Employment and Wages, Muenchener Wirtschaftswissenschaftliche Beitraege No. $00-13$.

Holmlund, B. 1998, Unemployment Insurance in Theory and Practice, Scandinavian Journal of Economics, 100(1), 113-141.

Koskela, E., Schöb, R., 1999, Alleviating Unemployment: The Case for Green Tax Reforms, European Economic Review 43, 1723-1746.

Layard, R., Nickell, S., 1990, Is Unemployment Lower if Unions Bargain over Employment?, Quarterly Journal of Economics, 105(3), 773-787.

Manning, A., 1991, The Determinants of Wage Pressure: Some Implications of a Dynamic Model, Economica, 58, 325-340.

Manning, A., 1995, Developments in Labour Market Theory and Their Implications for Macroeconomic Policy, Scottish Journal of Political Economy, 42(3), 250-266.

Oswald, A.J., 1985, The Economic Theory of Trade Unions: An Introductory Survey, Scandinavian Journal of Economics, 87(2), 160-193.

Ploug, N., Kvist, J., 1996, Social Security in Europe: Development or Dismantlement?, The Hague, London, Boston: Kluwer Law International.

Schmid, G., Reissert, B., 1996, Unemployment Compensation and Labour Market Transitions, in: Schmid, G., O’Reilly, J., Schömann, K. (eds.), International Handbook of Labour Market Policy and Evaluation, Cheltenham, UK and Northampton, MA, USA: Edward Elgar.

Schmid, G., Reissert, B., Bruche, G. 1992, Unemployment Insurance and Active Labor Market Policy. An International Comparison of Financing Systems, Detroit: Wayne State University Press.

Schluter, C. 1997, On the Performance of Social Benefit Systems, Economic Journal, 107, 489-502. 


\section{IZA Discussion Papers}
No. Author(s)
280
P. Apps
R. Rees
281
G. Saint-Paul
282
J. Albrecht
A. Björklund
S. Vroman
283
M. Hagedorn
A. Kaul
V. Reinthaler

284

H. Rapoport

A. Weiss

285
J. Jerger
C. Pohnke
A. Spermann

286

M. Fertig

C. M. Schmidt

287

P. Guggenberger

A. Kaul

M. Kolmar

288

D. A. Cobb-Clark

289

L. Cameron

D. A. Cobb-Clark

290

D. A. Cobb-Clark

M. D. Connolly

C. Worswick

291
Title

Area

Date

Household Saving and Full Consumption over

7

04/01

the Life Cycle

Information Technology and the Knowledge

5

04/01

Elites

Is There a Glass Ceiling in Sweden?

5

04/01

Welfare Analysis in a Schumpeterian Growth

7

04/01

Model with Capital

The Optimal Size for a Minority

1

$04 / 01$

Gut betreut in den Arbeitsmarkt?

5

Eine mikroökonometrische Evaluation der

Mannheimer Arbeitsvermittlungsagentur

First- and Second-Generation Migrants in

Germany - What Do We Know and What Do

People Think

Efficiency Properties of Labor Taxation in a

3

$04 / 01$

Spatial Model of Restricted Labor Mobility

Getting Ahead: The Determinants of and Payoffs

5

04/01 to Internal Promotion for Young U.S. Men and Women

Old-Age Support in Developing Countries:

3

04/01

Labor Supply, Intergenerational Transfers and Living Arrangements

The Job Search and Education Investments of

1

04/01 Immigrant Families

Cohort Effects in the Educational Attainment of

1

05/01

Second Generation Immigrants in Germany:

An Analysis of Census Data 
N. Smith

L. Husted
G. Brunello
C. Lucifora
R. Winter-Ebmer

300
A. Stutzer
R. Lalive

301

J. R. Frick

G. G. Wagner

302

G. S. Epstein

A. Weiss

303

G. A. Pfann

B. F. Blumberg

304

P. Cahuc

E. Wasmer firm Bargaining 

H. Bonin
G. Abío
E. Berenguer
J. Gil
C. Patxot

307

G. A. Pfann

308

G. A. Pfann

D. S. Hamermesh

309

G. Brunello

310

U. Sunde

311

G. Brunello

312

C. Furnée

M. Kemler

G. A. Pfann

313

A. Ferrer-i-Carbonell

B. M.S. van Praag
Is the Deficit under Control? A Generational Accounting Perspective on Fiscal Policy and Labour Market Trends in Spain 

A. Frederiksen
E. K. Graversen
N. Smith

Works Councils and Collective Bargaining in 

A. Ibourk
B. Maillard

The Matching Efficiency of Regional Labour Models 
